планируется разработка базовой технологии для сварки тонкостенных узлов и деталей применительно к потребностям данного предприятия ракетно-космической отрасли РФ. В дальнейшем будет развернуто единичное (мелкосерийное) производство автоматизированных комплексов электронно-лучевой аппаратуры и технологий для сварки тонкостенных узлов и деталей по индивидуальным заказам других предприятий. В настоящее время ведутся работы по поиску инвесторов и партнеров для участия в создании предлагаемой инновационной технологии и аппаратуры ЭЛС тонкостенных соединений. СибГУ приглашает всех заинтересованных в реализации проекта физических и юридических лиц к сотрудничеству.

$$
* * *
$$

1. Дружинина, А.А. Компенсация влияния магнитных полей на положение электронного пучка в процессе электронно-лучевой сварки / А.А. Дружинина, В.Д. Лаптенок, А.В. Мурыгин, Ю.Н. Серегин // Технологии и оборудование ЭЛС-2014: материалы III Санкт-Петербургской международной научно-технической конференции (24-26 июня 2014, г. Санкт-Петербург). С-Пб., 2014. С. $62-73$.

2. Позиционирование по стыку соединения при электронно-лучевой сварке в условиях действия магнитных помех: монография / А. А. Дружинина, В. Д. Лаптенок, А. В. Мурыгин, П. В. Лаптенок; Сиб. гос. аэрокосмич. ун-т. - Красноярск, 2017. 150 с.

3. Программа развития (дорожная карта) Сибирского государственного аэрокосмического университета имени академика М.Ф. Решетнева - опорного университета Красноярского края, Сиб. гос. аэрокосмич. ун-т. - Красноярск, 2016. 70 с.

4. Проект коммерциализации автоматизированного комплекса электронно-лучевой аппаратуры и технологий для сварки тонкостенных узлов и деталей /В. Д. Лаптенок, Г. И. Латышенко, Г.А. Карачёва, Е. М. Сычева, СибГУ, Красноярск, 2017. 55 с.

\title{
Медведева Е.В. \\ Особенности применения нормативно-законодательной базы при составлении консолидированной отчетности в условиях реорганизации компаний
}

Поволжский государственный университет сервиса (Россия, Тольятти)

doi:10.18411/spc-08-04-2018-18

idsp: 000001:spc-08-04-2018-18

Сравнение российских и международных нормативно-методических документов позволяет выявить существенные различия в отношении вопроса составления консолидированной отчетности при объединении и слиянии компаний. Вопросом, не решенным в российских документах нормативного и методического уровня, является вопрос определения стоимости объединения. Согласно МСФО 3 «Объединения бизнеса» стоимость объединения определяется как совокупная величина справедливой стоимости на дату обмена чистых активов приобретаемой компании, переданных покупателю в обмен на контроль над приобретаемой компанией и любых затрат, непосредственно связанных с объединением. Особое значение имеют установленные МСФО 3 категории «контроль» и «дата обмена», поскольку они доминируют при формировании бухгалтерской отчетности в случае объединения компаний. В российских нормативных актах и законодательных документах эти категории не прописаны.

В соответствии с МСФО 3 контроль - возможность определять (регламентировать) политику компании. Получение контроля предполагает приобретение одной из объединяющихся компаний более половины акций другой. Исключение представляют случаи, когда четко определено, что такой пакет акций не обеспечивает наличие контроля. Определение степени контроля, позволяющего признать результатом сделки по его приобретению объединение компаний, является 
ключевым вопросом, поскольку на следующем этапе возникает вопрос о необходимости составления единой (консолидированной или индивидуальной) отчетности. Кроме того, определение контроля важно и для определения даты приобретения, поскольку дата приобретения - это дата получения фактического контроля над приобретаемой компанией, что имеет особое значение для составления бухгалтерской (финансовой) отчетности.

В российских методических документах по составлению бухгалтерской (финансовой) отчетности при реорганизации компаний в отличие от международных, отсутствует термин «дата приобретения». Есть дата государственной регистрации образованной в ходе слияния единой компании, а также дата передачи имущества по передаточному акту, являющемуся фактически информационной базой для составления вступительной бухгалтерской (финансовой) отчетности, созданной в ходе реорганизации компании. При этом они могут не совпадать, что порождает вопрос достоверности оценки имущества и обязательств, в которой они должны отражаться во вступительной бухгалтерской отчетности. Кроме того, по российским правилам учета операций при объединении и слиянии оценка активов и обязательств при реорганизации компаний находится в компетенции учредителей. Подобный подход может стать причиной искажения информации о реальной стоимости активов и обязательств реорганизуемых компаний, недостоверности информации, отраженной во вступительной отчетности объединенной компании. МСФО 3 «Объединения бизнеса» решает данную проблему, признавая единственный вариант оценки активов и обязательств при покупке бизнеса - по справедливой стоимости на дату покупки.

Еще один важный момент, не прописанный в российских нормативных актах, это возможность приобретения компании по частям и обусловленная этим процессом проблема поэтапного определения стоимости объединения. В отличие от отечественных стандартов учета, МСФО 3 «Объединения бизнеса» регулирует данные вопросы: стоимость объединения равна совокупной стоимости отдельных операций покупки; дата обмена представляет дату осуществления каждой отдельной операции обмена. Поскольку российскими нормативными актами и методическим рекомендациями не рассматривается вопрос определения стоимости объединения и слияния, целесообразно обобщить правила ее установления, предусмотренные МСФО 3 «Объединения бизнеса». При формировании стоимости объединения включаются в его стоимость: справедливая стоимость приобретаемых чистых активов плюс затраты, непосредственно связанные с объединением. Определение стоимости объединения напрямую связано с вопросом оценки активов и обязательств интегрированных компаний. Положения отечественных и международных стандартов данного аспекта существенно различаются.

Методическими указаниями по формированию бухгалтерской отчетности при осуществлении реорганизации организаций, утвержденными Приказом Минфина РФ от 20.05.2003 г. № 44н, вопрос оценки активов и обязательств оставлен на рассмотрение сторон - участниц сделки [1]. МСФО 3 «Объединения бизнеса» предусматривает оценку по справедливой стоимости на дату приобретения. При этом указывается, что идентифицируемые активы и обязательства могут включать такие, которые ранее не признавались в финансовой отчетности приобретаемой компании, например, потому что до момента покупки они не соответствовали критериям признания. Российские же нормативные акты не регулируют вопросы признания в финансовой отчетности 
активов и обязательств, которые связаны с будущими убытками, доходами, расходами, которые компания планирует понести в результате объединения [2].

Несоответствие позиций в отношении оценки принимаемых к учету в результате объединения активов и обязательств влечет за собой существенные расхождения в таких показателях, как чистые активы и деловая репутация, рассчитываемых на основе учетной информации, сформированной согласно положениям отечественных и международных стандартов учета и бухгалтерской (финансовой) отчетности.

МСФО «Объединения бизнеса» призывает покупателя учитывать чистые активы экономического субъекта по их справедливой стоимости на дату покупки. В соответствии с российскими стандартами - по их балансовой стоимости. Учитывая важность такого соотношения, как чистые активы - величина уставного капитала для оценки уровня финансовой устойчивости компании, можно сделать вывод, что эти расхождения могут стать причиной недостоверной информации о реальном финансовом состоянии организации [3]. На основе информации о стоимости покупки и стоимости активов и обязательств интегрируемых компаний может быть рассчитан показатель «деловая репутация» (гудвилл) имеющий особое значение для инвестора, так как его положительная величина фактически является надбавкой к цене, уплачиваемой покупателем в ожидании будущих экономических выгод, то есть характеризует инвестиционную привлекательность приобретаемой компании.

В отношении гудвилла между российскими и международными стандартами также существуют разногласия. Не считая несоответствия в оценке, участвующих в расчете активов и обязательств, различие состоит и в формировании учетной информации по данному показателю, подлежащей отражению в отчетности. Согласно ПБУ 14/2007 «Учет нематериальных активов», приобретенная деловая репутация организации амортизируется. Амортизационные отчисления по положительной деловой репутации отражаются в бухгалтерском учете путем равномерного уменьшения ее первоначальной стоимости (предусмотрен линейный способ). Отрицательная деловая репутация в полной сумме относится на финансовые результаты в качестве прочих доходов. Согласно МСФО 3 «Объединения бизнеса» гудвилл не подлежит амортизации. Вместо нее предусматривается ежегодная переоценка независимо от наличия индикаторов обесценения, перечень которых установлен в МСФО 36 «Обесценение активов» .

Таким образом, российские стандарты учета и отчетности, а также методические указания по составлению отчетности при реорганизации компаний не раскрывают многие актуальные вопросы, возникающие в ходе объединения и слияния, либо содержат положения, не соответствующие логике международных стандартов. Это порождает объективные трудности при осуществлении учета процессов интеграции и составлении отчетности интегрируемыми компаниями. Необходима разработка российского стандарта по учету объединений и слияний, положения которого должны соответствовать условиям рыночной экономики, обеспечивать формирование достоверной учетной информации об образованной в результате интеграции компании, позволяющей дать объективную оценку ее инвестиционной привлекательности. Основой такого стандарта должно стать определение сущностных критериев сделок объединения и слияния: условий их признания, механизмов осуществления, организационных структур, образуемых в ходе интеграции компаний, а следовательно, вида бухгалтерской (финансовой) отчетности. Особое внимание следует уделить вопросам признания в учете оценке активов, обязательств объединяемых компаний, 
разработке объективных критериев обесценения, созданию резервов под обесценение финансовых вложений, резервов на реструктуризацию объединенного бизнеса. Важнейшим для рассмотрения является вопрос определения такого показателя, как гудвилл, формально характеризующего инвестиционную привлекательность образованной в ходе объединения компании: его оценка и переоценка, особенности распределения по единицам, генерирующим денежные средства.

$$
* * *
$$

1. Российская Федерация. Приказ. Методические указания по формированию отчетности при реорганизации организаций [Электронный ресурс]: федер. закон № 44н: принят Министерством Финансов РФ 20.05.2003 г. (в редакции от 25.10.2010 г. № 132н) // Консультант Плюс

2. Насакина Л.А. Методы сбора и анализа экономической информации в обосновании стратегических управленческих решений / Л.А. Насакина // Вестник Поволжского государственного университета сервиса. Серия: Экономика. 2012. № 24. С. 130-136.

3. Шнайдер О.В. Актуальные вопросы оценки стоимости бизнеса экономического субъекта / О.В. Шнайдер // Вопросы региональной экономики. 2017. Т. 31. № 2. С. 156-162.

\section{Насакина Л.А. \\ Некоторые вопросы формирования управленческой учетной политики экономического субъекта}

Поволжский государственный университет сервиса (ПВГУС)

(Россия, Тольятти)

doi:10.18411/spc-08-04-2018-19

idsp: 000001:spc-08-04-2018-19

\section{Аннотация}

Разработка управленческой учетной политики экономического субъекта представляет собой многоэтапный процесс, обеспечивающий создание фундаментальной основы осуществления управленческого учета и составления отчетности по отдельным структурным подразделениям организации. Управленческая учетная политика в отличие от учетной политики для целей финансового учета позволяет осуществлять подготовку более аналитической информации и устанавливать не только финансовые критерии оценки деятельности внутренних сегментов экономического субъекта, но и включать нефинансовые данные. Такой подход к разработке управленческой учетной политики обеспечивает эффективную организацию управленческого учета в экономическом субъекте и возможность использования его данных как для оперативного управления деятельностью организации и ее структурных подразделений, так и для установления стратегических ориентиров для будущей деятельности с учетом внутренних потребностей и новых вызовов внешней среды.

Ключевые слова: управленческий учет, учетная политика, внутренняя отчетность.

\section{Abstract}

Development of management accounting policy of an economic entity is a multi-stage process that provides the creation of a fundamental basis for the implementation of management accounting and reporting on individual structural units of the organization. Management accounting policies, unlike accounting policies for financial accounting purposes, allow for the preparation of more analytical information and establish not only financial criteria for assessing the activities of internal segments of an economic entity, but also to include non-financial data. This approach to the development of management accounting policy ensures the effective organization of management accounting in the economic entity and the ability to use its data for the operational management of the 